\title{
Rafting the rapids 2005 Searching for our future purpose
}

A uthor's note: The catalyst for my thoughts is the preliminary environmental scan of the 2004 Access and Delivery Team at the University of Arizona: Krisellen Maloney, Doug Jones, Ray Swedenburg, and Veronica Reyes. The thoughts are my own.

\section{Creativity}

In the rst essay in this series, Frances Maloy noted, While I do not have an exact vision of what the future of learning, teaching, and research will look like, I do know that learning, teaching, and research will be different from how it is done today, and then challenged us to engage in original thinking about our core purpose. Building on that, Bob Martin stated: We need to embrace a bold new vision of learning. We need to think beyond our institutional boxes . ${ }^{1}$

These essays were written prior to the December 14th announcement by Larry Page, Google cofounder and president of products: Today we re pleased to announce this program to digitize the collections of these amazing libraries so that every Google user can search them instantly . Google s mission is to organize the worlds information, and we re excited to be working with libraries to help make this mission a reality. ${ }^{2}$

And prior to this announcement of December 15, 2004 by the Internet Archive: Today, a number of international libraries have committed to putting their digitized books in open-access archives, starting with one at the Internet Archive. This approach will ensure permanent and public access to our published heritage . In this way we are getting closer to the goal of Universal Access to All Knowledge. ${ }^{3}$
And all of this happened after the ACRL University Libraries Section Public Services Directors of Large Libraries Discussion Group meeting, June 2004, at which the rst response to a question asking what the top ten issues are was: They can nd it in Google. Another was What value-added services do we add? another way of saying, What is our core purpose?

At the University of Arizona (UA) Library, we seemed prepared for all these questions and these announcements. In the spring of 2004, we formed the Access and Delivery Team and charged them to: Investigate and analyze several trends and assumptions including but not limited to rapidly declining budgets, changing focus and philosophy of the University, increased availability of technology, changing customer expectations for access to and delivery of information to evaluate their relevance and impact in our environment. Identify and recommend principles, strategies, and priorities that will guide us to effectively provide access to and deliver information and realize our vision for the library in 2013 (and beyond).

While 2013 did seem a stretch, brie y, it felt like we were creative and might be able to stay ahead of the curve. We knew that changes in the scholarly communication process would affect how we would do business in the future. We knew that e-learning trends appeared to peak and fall as the projected

Shelley Phipps is assistant dean for team and organization development at the University of Arizona, e-mail: phippss@u.library.arizona.edu

○ 2005 Shelley Phipps 
revolution in teaching hit the cultural barriers of a classroom- and seat-focused higher educational system. We knew that technical infrastructure mattered and we needed to reengineer it, but it wasn $t$ what we existed to do. We had already formed a Document Delivery Team two years earlier, and we thought this was an area that would grow rapidly. We knew that traditional reference service was on the decline, and we created a team that has restructured our reference service staf ng desks with well-trained classi ed staff, eliminating a separate reference and circulation desk in our Science Engineering and Fine Arts branch libraries, creating a robust subject reference referral system, and expanding virtual reference hours. And we had begun to speculate about how the Google search engine could change the world and our mission. Last year, we at the UA Library had congratulated ourselves on writing a succinct, direct mission statement: We connect our customers to information that furthers their education and research goals.

\section{... and leadership}

Then Google announced its IPO, followed by a 3rd quarter nancial report of $\$ 1.86$ billion in cash.

It is interesting to compare our mission to Google s mission: Google s mission is to organize the worlds information and make it universally accessible and useful. ${ }^{4}$ And: Our two chief competitive advantages are surprise, innovation and an almost fanatical devotion to our users. 5 Hmmmm.

We thought we had planned for this. We were customer focused, we were team based, we were a learning organization, we did strategic planning, we implemented process improvement, we continued to increase service quality and to reduce costs and reduce the need for mediation to respond to the growing expectation for self-suf ciency and access from the desktop.

But we hadn t really planned for this: Harvard University, University of Michigan, Stanford University, Oxford University, the New York Public Library and the digitiza-

\section{We are all searching for our future purpose. We ride the whitewater of change, hoping for a calm place to put out (as we river runners say); restrap our gear; tend our ropes, bungee cords, and carabiners; look for tears; check our food supply and bailing equipment; and catch our breaths... and decide which fork in the river to pursue.}

tion of a very large portion of the world $s$ information presently not copyrighted, with Google. Google has a vision and principles. They have Ten Things They Have Found to Be True: 1. Focus on the user and all else will follow. 2. It s best to do one thing really, really well. 3. Fast is better than slow. 4 . Democracy on the Web works. 5. You don t need to be at your desk to need an answer. 6. You can make money without doing evil. 7. There s always more information out there. 8. The need for information crosses all borders. 9. You can be serious without a suit. 10. Great just isn $t$ good enough. They have partners: scholarly publishers, national libraries, OCLC. ${ }^{6}$

Google access to OCLC s Worldcat Google access to our library s catalog. Google Print. Google Scholar. Google Local Search. Google News Headlines. Google Phone Book.

But I go on too much about Google news (too many zeros!). There is Yahoo. OCLC is rethinking its mission. The Center for Research Libraries considers a variation of roles it could play. Wiley announces its entrance into the e-learning market with eGrade Plus, a powerful online tool that provides instructors with an integrated suite of teaching and learning resources in one easy-to-use Web site. Assisting faculty to prepare, present, track student progress, administer their courses. ${ }^{7}$

Elsevier makes searching the scienti c literature easier: Amsterdam, 21 December, 2004 Elsevier announced today that its free science-speci c search engine, Scirus, has introduced a new version of its downloadable toolbar. The toolbar includes indispensable 
new functionalities for nding scienti $\mathrm{c}$ information on the Web, and enables users to search directly on Scirus or through Scirus Web Sources and/or Journal Sources, from anywhere on the Internet. ${ }^{8}$

\section{In the rapids: What will our mission or core purpose be?}

We are all searching for our future purpose. We ride the whitewater of change, hoping for a calm place to put out (as we river runners say); restrap our gear; tend our ropes, bungee cords, and carabiners; look for tears; check our food supply and bailing equipment; and catch our breaths and decide which fork in the river to pursue.

What will our future users need to learn to nd, select, obtain, evaluate, create, and utilize information? Will all information be searchable in ways that meet our customers changing expectations, or will there continue to be a role for librarians in teaching resource selection and search techniques? Once an information resource is identi ed, will users be able to tell what is high quality and scholarly or will we continue to teach resource assessment? How will the publisher of the information resource know which users have licensed access to information? Will the implementation of authentication and authorization mechanisms become so cumbersome for both the publisher and the library that pay-per-view methods will prevail? How will simpli ed access to information affect the need for course reserves, document delivery, and interlibrary loan?

What will our role be in partnering with faculty to develop courses? Will the endeavors by publishers to create interactive courseware in addition to traditional texts be adopted by faculty? What support will faculty need when publishers are creating easy-to-modify learning objects?

Will we play a role in digitizing? just our unique archival collections? Will a collaborative or Google provide the digitization labs? Once our unique materials are digitized, will we continue to make them available free for research and learning? Or will we institute pay-per-view, or print-on-demand, so we can recover costs for continuing to provide these unique research materials?

Will we continue to build collections? Oh, I know, there will always be books. And for at least ve more years the dominant form will be print. Then what? Will we be billed on a pay-per-view basis by publishers? Will we pay up front for so many uses per the rst three years then pay for archiving the copyrighted material in an open-access archive? How will we manage the collections we have licensed or otherwise contracted for access to? Will our principles regarding licensing encourage users to work with publishers directly? How will we know what is not available electronically and who is buying it and how to borrow on demand to meet the insatiable need for immediate access? Won $t$ the publishers set the standard? Can we lead? Or can we just follow, creatively?

Frances quoted me in her rst editorial. I vaguely recall the frustration behind it: The issues facing libraries shouldn t be viewed as all this bad stuff happening to us but as opportunity for transformational change. ${ }^{9}$ But, I need to gulp, now, and add: How do we transform while on the whitewater?

\section{If we add value, they will come}

This is the reality of the current economic world. Do we know what our customers want? Once we do do we have agile ways of responding? Can we be creative? Can we lead creativity? Can we respond strategically? Can we decipher a strategic vision for ourselves? Can we commit to it, develop strategies, and manage strategically?

In their recent book on strategic management, Fitzroy and Hulbert note that to survive and achieve sustainability of success, we must develop new opportunities/competencies AND exploit existing opportunities/competencies. ${ }^{10}$ What strategies will we pose and experiment with as our response to this whitewater, Googlized environment? What is our passion? What are we prepared to lead? What value-added change can we contribute to the learning environments that Frances and Bob have outlined? New competencies and 
new strategies may change the scope of our libraries. Are we ready for this challenge?

What is our anchor? What do we build on? How about ALA s Principles for the Networked World? Can we provide room for all people s voices and protect the rst amendment rights of all? Can we ensure that people have privacy and con dentiality in their use of information? Can we keep the cost of information access fair and equitable? Can we help realize fair use, rst sale, and other library and educational exceptions in the networked world? Can we provide approaches, methods, and access points that meet the unique needs and circumstances of all people? Can we be agile enough to discover our new role in helping students and faculty gain the ability to identify, locate, evaluate, create, and use information effectively, critically, and ethically? ${ }^{11}$ These are some of the principles we must instill in those who will work for Google and will create the new infrastructures. But these are also principles which, unless applied with critical intelligence and understanding of the needs of researchers, can in uence users to bypass the library and work with publishers directly.

Can we create strategies quickly? Can we gain the new competencies for the networked world fast enough to play a leadership role? What are they? Can we restructure our academic libraries to hire and reward differently? To plan and decide quickly and innovatively? To collaborate, truly? Or is it too late? It is probably too late to plan carefully. Can we learn to risk, assess, revise, and be as entrepreneurial as Google? Can we learn to love surprises? Can we collaborate, truly?

I think these are the biggest questions. They will take the most creativity. And they will take leadership in the largest sense. Collaborative leadership, based on vision and principles. With all involved and empowered. With all ideas considered. River runners understand this approach. A shared vision. A felt passion. And everyone rowing, scouting, making instantaneous decisions based on full understanding and agreement on strategy. And consistently as-

\section{What strategies will we pose and experiment with as our response to this whitewater, Googlized environment? What is our passion? What are we prepared to lead?... New competencies and new strategies may change the scope of our libraries. Are we ready for this challenge?}

sessing the progress of the journey. The white water is a reality. Everyone aboard?

\section{Notes}

1. F. Maloy s Creativity as a Leadership Strategy in Times of Change, CERL News 65, no. 8 (2004): 444; and R. F. Martin, Libraries and Librarians in the $21^{\text {st }}$ Century, "CERL News 65, no. 11 (2004): 671.

2. Google Checks Out Library Books www.google.com/intl/en/press/pressrel/ print_library.html.

3. International Libraries and the Internet Archive Collaborate to Build Open-Access Text Archives, www.archive.org/iathreads/ post-view.php?id=25361.

4. Google Corporate Information, Company Overview, www.google.com/corporate/.

5. Google Corporate Information, Google History http://www.google.com/corporate/ history.html.

6. Google Corporate Information, Our Philosophy, www.google.com/corporate/ tenthings.html.

7. About eGrade Plus, he-cda.wiley. com/WileyCDA/Section.rdr?id=101003.

8. Scirus Launches New Toolbar, www. elsevier.com/wps/ nd/authored_newsitem. cws_home/companynews05_00222.

9. Maloy, Creativity as a Leadership Strategy in Times of Change, 446.

10. Peter FitzRoy and James M. Hulbert, Strategic Management: Creating Value in Turbulent Times (Chichester, UK: John Wiley \& Sons, 2004).

11. Principles for the Networked World, (Chicago: ALA, 2003), www.ala.org/ala/washoff/washpubs/principles.pdf. z 